\title{
Psychotherapeutic change in children and adolescents who have been sexually abused: A model from participants' perspectives
}

\author{
Claudia Capella, Loreto Rodríguez, Estrella Azócar, Ximena Lama, Lucía Núñez, Daniela Águila, Camila Gómez, \\ Macarena Espeleta, Vania Vásquez
}

Department of Psychology, Faculty of Social Sciences, University of Chile, Chile

Correspondence: Claudia Capella, Department of Psychology, Faculty of Social Sciences, University of Chile, Chile. Capitán Ignacio Carrera Pinto, 1045, Nuñoa, Santiago de Chile, postcode 7750000. Tel.: 229772410.

E-mail: ccapella@u.uchile.cl

Citation: Capella, C., Rodríguez, L., Azócar, E., Lama, X., Núñez, L., Águila, D., Gómez, C., Espeleta, M., \& Vásquez, V. (2022). Psychotherapeutic change in children and adolescents who have been sexually abused: A model from participants' perspectives. Research in Psychotherapy: Psychopathology, Process and Outcome, 25(1), 89-101. doi: 10.4081/ripppo.2022.583

Acknoowledgements: the authors would like to thank the project research team that made this study possible, as well as the centres and participants. The participating centres are connected with the following institutions: CAVAS from Policía de Investigaciones de Chile, Corporación Opción, Fundación Ciudad del Niño, and Fundación Mi Casa.

Contributions: CC participated and led different phases of the research and writing process, contributing to analysis, writing and revising the article; LR contributed to analysis, drafting and writing; EA contributed to analysis, drafting and writing; XL contributed to analysis; LN contributed to analysis; DA contributed with analysis; CG contributed to analysis and literature review; ME contributed to analysis and literature review; VV contributed to analysis and literature review.

Funding: this work was supported by the National Commission for Scientific and Technological Research (CONICYT) of Chile, under Grant Project Fondecyt $N^{\circ} 11140049$.

Conflict of interest: the authors declare no potential conflict of interest.

Ethical approval and consent to participate: ethical approval was obtained from the Committee on Ethical Research in Social Sciences through the Faculty of Social Sciences at the University of Chile where the leading author works. Consent or assent to participate was obtained from all participants and centres.

Availability of data and material: the authors state the availability of data and material, but not for dissemination.

Received for publication: 14 September 2021.

Revision received: 2 February 2022.

Accepted for publication: 14 February 2022.

This work is licensed under a Creative Commons Attribution NonCommercial 4.0 License (CC BY-NC 4.0).

${ }^{\circ}$ Copyright: the Author(s), 2022

Licensee PAGEPress, Italy

Research in Psychotherapy:

Psychopathology, Process and Outcome 2022; 25:89-101

doi:10.4081/ripppo.2022.583

\begin{abstract}
Change in psychotherapy research in cases of child sexual abuse (CSA) has mainly emerged from a symptomatologic view, which needs to be complemented by a subjective perspective of change. Thus, this article aim is to describe different outcomes and stages of change during psychotherapy in children and adolescents who have been sexually abused, from the subjective perspectives of those involved in the process. A longitudinal qualitative study was developed. Qualitative interviews were conducted at different moments of the psychotherapeutic process (at around 6 months of therapy, 12 months and at the end of therapy) with 28 children and adolescents aged 6 to 17, with their caregivers and therapists. All children and adolescents attended and then completed psychotherapy due to sexual abuse in natural settings, in public specialized centres in Santiago, Chile. Sexual abuse occurred mainly in an intrafamilial context or by acquaintances. Data analysis was conducted using narrative analysis. Three stages of therapy were identified: i) settling into therapy; ii) approaching CSA; and iii) healing from abuse. Three different outcomes of psychotherapeutic change were also identified: i) protective and psychosocial changes; ii) changes related to diminishing the effects of abuse; and iii) changes related to healing from abuse. Psychosocial characteristics of the cases and features of the therapeutic process are described in each group. The outcomes of change and the stages of therapy are interrelated in a dynamic and gradual process where change is linked with the case's psychosocial characteristics and the features of the therapeutic process. Results allowed the authors to situate the voices of the participants within a proposed model of psychotherapeutic change for CSA, with clinical practical implications.
\end{abstract}

Key words: Sexual abuse; children; adolescents; psychotherapeutic change; narrative; subjective perspectives.

\section{Introduction}

Child sexual abuse (CSA) is a significant and prevalent issue, which is experienced by $18-20 \%$ of women and $8 \%$ of men worldwide (Barth, Bermetz, Heim, Trelle, \& Tonia, 2013). Existing literature indicates that these experiences often lead to negative consequences, both in the short and the long term, affecting a child's development in many different areas, including their psychological well-being (Guha, Luebbers, Papalia, \& Ogloff, 2019), being sexual abuse a precursor of several psychopathology diagnosis in adulthood (Zarrella et al., 2017). Some authors have studied the influence on the consequences 
of the relationship with the perpetrator, finding differences depending on if the aggressor is from the family context or not (Guerra, Farkas \& Moncada, 2018).

Psychotherapy is a fundamental aspect in the treatment and support provided to victims of CSA (HetzelRiggin, Brausch, \& Montgomery, 2007; Tichelaar, Deković, \& Endendijk, 2020). A main objective of psychotherapy with children and adolescents who are victims of CSA is to integrate this experience into their life continuum and personal story (Capella \& Gutierrez, 2014; Narang, 2016).

One of the most studied clinical treatments for children and adolescents who have lived CSA and traumatic experiences is cognitive-behavioral therapy (CBT) (Cohen \& Mannarino, 1998; Cohen, Mannarino, \& Deblinger, 2012), including studies on treatment outcomes and symptomatologic change. However, Tichelaar et al. (2020) though a recent systematic review indicate there is no conclusive data concerning the effectiveness of a type of psychotherapy over another type, existing diverse forms of treatments for CSA victims and the range of consequences they diminish. In this regard, the literature suggests that having therapy might be better than not having any treatment when facing the adverse effects of CSA and that different types of therapy could benefit differently children and adolescents with diverse characteristics (Hetzel-Riggin et al., 2007; Tichelaar et al., 2020).

Research with adults suggests that the process of healing from sexual abuse and re-signifying the experience occur at different stages and through various aspects of the person's life such as their interpersonal relationships and their personal growth around the event (Draucker et al., 2011). This is a nonlinear process involving moments of both progress and being setback (Banyard \& Williams, 2007). Draucker et al. (2011) propose a theoretical model for the process of healing from sexual abuse, which incorporates the participant voices of adults who were victims of CSA and researches healing outside of a therapy setting.

In clinical psychology research, psychotherapeutic change has been studied to understand how it occurs and what factors are involved in change within various theoretical models of psychotherapy (Altimir et al., 2010). There are different definitions of change, primarily grouped around ideas of symptomatic change or subjective change. Looking at change from a subjective perspective, it can be understood as a set of interpretations and subjective narratives that help develop new behaviours, which lead to new patterns of interaction and to new subjective theories and meanings of experiences (Altimir et al., 2010; Gonçalves, Matos, \& Santos, 2009; Krause, 2011). Research proposes that subjective change, as a nonlinear process, is organized into stages with progressive levels of complexity, which begin before therapy and continue after therapy is concluded (Altimir et al., 2010; Krause, et al., 2007; Krause, 2011).

Research on psychotherapeutic change has a long tra- dition of including patients' perspectives (Elliot, 2008), but has focused predominantly on knowing how change occurs in adults with only a few studies having considered children and adolescents' perspectives (Alamo, 2019; Areas, Olivera, \& Roussos, 2020; Capella et al., 2016; Capella, Gutierrez, Rodriguez, \& Gomez, 2018; Carlberg, Thorén, Billström, \& Odhammar, 2009). Existing research on change in children and adolescents has been largely based on reports by adults such as caregivers or psychotherapists and the perspectives of younger children have rarely been included, perhaps due to methodological and ethical challenges (Carlberg et al., 2009; Migdley, 2004).

Studies which have included children and adolescents' perspectives on subjective change in psychotherapy have emphasized various aspects of the observed change, highlighting the importance of contextual dimensions such as caregivers, school and the therapeutic setting, and changes produced in different areas of children's development such as identity, behavior, affections, or their cognitive strategies (Alamo, 2019; Areas et al., 2020; Capella et al., 2018; Castrillón, 2020). More specifically, research in psychotherapy with children and adolescents who have been victims of sexual abuse has focused predominantly on measuring symptomatologic change (Sanchez-Meca, Rosa-Alcázar, \& López-Soler, 2011; Tichelaar et al., 2020). There is limited research on children and adolescents' subjective views of their changes during therapy and how this affects the development of new narratives and behaviours related to the traumatic experience (Capella et al., 2018).

Certain studies have described children and adolescents' perceptions of their healing process from sexual abuse and the psychotherapeutic change due to this experience, which in few cases also included the views of caregivers and/or therapists (Aguila et al., 2016; Capella et al., 2016, 2018; Dussert et al., 2017; Farr et al., 2021; Foster \& Hagedorn, 2014; Jessiman, Hackett, \& Carpenter, 2017; Nelson-Gardell, 2001). These studies demonstrate that while overcoming CSA is a difficult process, psychotherapy can help children and adolescents to heal from the abuse and to feel personal growth, which in turn enables them to give new meaning to the abuse and integrate the experience into their personal narrative. Furthermore, psychotherapy allows them to imagine new personal goals for the future. Additional external factors also affect the process of change and healing such as school, family and friends, which can support and facilitate these processes of change. Conversely, a lack of family support or secondary victimization at the judicial process can hinder change in children (Capella et al., 2016, 2018; Farr et al., 2021; Foster \& Hagedorn, 2014; Jessiman et al., 2017). Studies may also describe the process of change as progressive and gradual (Capella et al., 2018).

Many of these studies include the views of participants at only one stage of therapy (Capella et al., 2016, 2018; 
Farr et al., 2021; Jessiman et al., 2016) or focus on an analysis of written materials produced by participants during therapy (Foster \& Hagedorn, 2014). However, it is necessary to understand children and adolescents' perspectives on psychotherapeutic change during multiple moments of therapy as it improves an overall understanding of how this process develops in this age group. Moreover, in order to establish a more complete understanding of change in child and adolescent psychotherapy, including all the participants in the process, research must explore not only the perspectives of children and adolescents, but also the views of their caregivers and the therapists (Alamo, 2019; Altimir et al., 2010; Castrillón, 2020; Fernández et al., 2016; Midgley et al., 2018).

This study investigates the stages and outcomes of psychotherapy and explores how subjective psychotherapeutic change happens in children and adolescents who have been victims of sexual abuse, and possible variations in this process. This study incorporates the diverse perspectives of children and adolescents, their caregivers and psychotherapists, and includes a longitudinal element as it follows the progression of the psychotherapeutic process. Thus, this study contributes to existing literature on psychotherapeutic work with children and adolescents who have been victims of sexual abuse through its more complete understandings of all those involved in the process, and due to complementing the main symptomatologic view of change in existing studies, with a subjective perspective of change.

\section{Methods}

\section{General design}

The present study is a piece of longitudinal, qualitative research, which analysed the perspectives of participants at different moments of the psychotherapeutic process. Employing multi-case analysis, the study aimed to capture an in-depth view of participants' understandings of the psychotherapeutic change process.

Studied therapies developed in natural clinical settings and the sample was obtained through six different public centres which provide specialized treatment for sexual abuse and maltreatment in Santiago, Chile. All six centres belong to the same collaborative network and are funded by the National Child Service [SENAME], the institution in charge of children's welfare in Chile (which since recently is called MejorNiñez). SENAME (2019) establish a set of intervention guidelines for these centres in which therapies typically last 12 months and have the opportunity to acquire an extension, usually for a total of 18 months or sometimes more. According to these guidelines, the specialized therapy focuses on three main areas: protecting children from new risk situations or violence, helping them to establish new meanings to the sexual abuse and strengthening familial resources. Predomi- nantly, the interventions with children and adolescents are carried out by a psychologist with a psychotherapeutic approach and a social worker who takes part in the intervention with caregivers, creating a psychosocial intervention model. All the cases which begin therapy in these centres come with a legal report regarding the abuse.

\section{Participants}

The total sample of the research project was composed of 40 cases, each of which included three different types of interrelated participants: children and adolescents, their caregivers and their therapists. Inclusion criteria considered children and adolescents who were 6 to 17 years old at the beginning of therapy, were victims of sexual abuse (according to a professional's assessment) and were currently undergoing a psychotherapeutic process in a specialized centre due to that experience. Theoretical sampling was employed because the cases were expected to represent different possible positions based on the attributes used to characterize the participants (Valles, 2003) such as age, type and chronicity of abuse and relationship with the abuser. Thus, in terms of age, there were included children 6-11 years old and adolescents aged 12 to 18; about type of abuse there were included children and adolescents' victims of abuse (without penetration) and rape (penetrative contact); regarding chronicity the abuse was repeated or chronic (occurred in several times, or even during years), or was in a single occurrence (in some cases this information was unknown). And about the relationship with the abuser, in some cases abuse occurred in the family context, being the aggressor a parental figure (father or stepfather) or other relative (grandfathers, uncles, cousin, brothers, brother-in-law), and in some cases the aggressor was an acquaintance (such as friends of the family, neighbours) (in some cases this data was unknown).

Children with severe symptomatology (as psychotic symptoms, for instance) were excluded from participating, to protect them from any foreseeable difficulty that participation in the research may cause.

However, not all the cases completed psychotherapy and in some of the cases we were only able to have one perspective (for example, the one of the therapist) or only interviews at one moment of therapy (for example, the beginning). Therefore, for this paper, where the focus is on stages and outcomes of psychotherapeutic change, we select the cases that completed therapy and that have interviews from the three perspectives (children/adolescent, caregiver and therapist) and have interviews at least in two moments of therapy. Thus, the sample of this paper considers 28 cases. Table 1 displays the specific characteristics of the sample. Cases who dropout of therapy (which were mainly adolescents) are reported elsewhere (Capella, Nuñez, Vásquez \& Fuentes, 2020).

The sample comprises children and adolescents between 6 to 17 years old (average age of 10.3 years old), who presented mostly with emotional, behavioral and 
post-traumatic symptoms at the beginning of therapy. The average length of time in treatment in the sample was 20 months with a minimum of 7 months and a maximum of 28 months. The characteristics of the abusive experience in the sample were similar to those described in cases attending similar centres in Chile (Gómez, Cifuentes, \& Sieverson, 2010), occurring mainly in an intrafamilial context or by acquaintances, in a repeated or chronic recurrence, and victims being mainly women.

There were more female than male therapists $(75 \%$ females and 25\% males). Therapists ranged in age from 24 to 46 years old, had from 1 to 19 years of clinical experience and had from 3 months to 15 years of experience in specialized sexual abuse psychotherapy. Psychotherapy was guided by different theoretical approaches, primarily a systemic $(54 \%$ of the therapists of the cases in the sample), cognitive-constructivist (35\%) or psychoanalytic approach (11\%). It is important to note that few of the therapists included in the sample provided psychotherapy to more than one child or adolescent in the sample. Additionally, in 19 cases, there was a change of psychotherapist (due to the therapist leaving the centre/changing job) during therapy at different stages of the process. The therapist that was interviewed was the one that was performing the therapy at the moment of the interview. However, for practical reasons, the characteristics of therapists described in the paper are the ones of the first therapist in all cases.

Caregivers who took part in the psychotherapeutic process with their children and participated in the research study were predominantly mothers. In five cases, the main caregiver was another female figure such as a grandmother, while in just one case, a male figure, the father, was in charge of supporting the therapy process. In the remaining case, an aunt and the uncle were in charge of the child. The caregiver who participates in the research was the main carer of the child or adolescent, and who was supporting and accompanying the child therapeutic process.

\section{Data collection}

Ethical approval was obtained from the Committee on Ethical Research in Social Sciences through the Faculty of Social Sciences at the University of Chile. Permission from the six centres' authorities was then requested and received. With these endorsements, initial meetings were conducted with the selected cases toward the beginning of their therapy at which time they were invited to partic- ipate in the study. In cases where they agreed to participate, therapists and caregivers signed an informed consent letter while children provided their assent. Each therapist also completed a case characterization form, and symptomatologic scales were completed by caregivers and children and adolescents at the beginning and end of therapy; however, those results will not be reported here, thus, more details about these scales won't be provided here.

Interviews were then conducted at different moments of the psychotherapeutic process. An initial interview was conducted approximately six months after therapy started; a second at approximately 12 months; and a final interview was conducted when the child or adolescent was discharged from psychotherapy if therapy lasted longer than 12 months. A period of approximately six months passed between each set of interviews. While contacts were made throughout therapy, in some cases it was not possible to obtain all three perspectives (child or adolescent, caregiver and therapist) on all moments, due to several factors including some participants withdrawing from the study, declining participation and scheduling availability. Additionally, for some cases discharged at 12 months of therapy, only two interviews were obtained. However, all the cases have interviews with the three perspectives and at least two moments of interviews. A total of 200 interviews were conducted (see Table 2).

Data was collected through qualitative interviews, which made it possible to preserve participants' subjec-

Table 1. Sample characteristics.

\begin{tabular}{llc}
\hline Characteristic & Categories & Number \\
\hline Age & Children aged 6-11 years & 19 \\
& Adolescents aged 12-17 years & 9 \\
\hline \multirow{2}{*}{ Gender } & Females & 22 \\
& Males & 6 \\
\hline Offender & Paternal figure & 4 \\
& Other relative & 19 \\
& Acquaintances & 3 \\
& Unknown & 2 \\
\hline \multirow{2}{*}{ Type of abuse } & Sexual abuse (without penetration) & 22 \\
& Rape (penetrative contact) & 6 \\
\hline \multirow{2}{*}{ Chronicity of the abuse } & Repeated or chronic & 14 \\
& Single occurrence & 10 \\
& Unknown & 4 \\
\hline
\end{tabular}

Table 2. Interviews carried out.

\begin{tabular}{lcccc}
\hline & Moment 1 (approx. 6 months) & Moment 2 (approx. 12 months) & Moment 3 (approx. 18 months) & Total interviews \\
\hline Caregivers & 25 & 18 & 19 & 62 \\
\hline Children and adolescents & 26 & 18 & 19 & 63 \\
\hline Therapists & 26 & 26 & 23 & 75 \\
\hline Total & 77 & 62 & 61 & 200 \\
\hline
\end{tabular}


tivity (Valles, 2003). To achieve this, an interview script was developed, which started with an open encouragement to create a narrative about the psychotherapeutic process (example: tell me how has been to participate in therapy at this centre). Overall, the script considered five main topics: expectations in psychotherapy (examples: did you want to come? you think therapy can help you?); the content of change (examples: there have been changes in therapy? Which changes? How have you notice these changes?); the evolution of change and the psychotherapeutic process (examples: how did the changes developed? what do you like about therapy? Was there a special moment you remember about therapy?); relationships in psychotherapy (examples: how is the relationship with your psychologist? What do you like about him/her?); and factors which can hinder or facilitate change (examples: what things or persons help to change? What makes change more difficult?). Using the script, a similar interview structure was produced with each of the participants at the different data collection points. There were also some differences across the interviews depending on the participant (examples: parents where ask about changes in their children and on them; relationship of the child with the psychologist and of them with the psychologist and social worker; therapist where asked about the process with this case in their role of therapist), the moment of interview (example: at the final interview questions were asked about the discharge process from therapy) and the use of child-friendly language and visual material in the case of children (for example, drawings).

All interviews took place in the six centres the families attended and were conducted by members of the research team who were not connected to the psychotherapeutic process. In keeping with ethical standards, the research team was assisted by the psychotherapists working with each case to conduct interviews at times that would not interfere with the psychotherapeutic process.

\section{Data analysis}

Data analysis was conducted across three phases using narrative analysis (Riessman, 2008). In the first phase, each individual interview was transcribed and analysed using thematic narrative analysis, complemented with the visual narrative analysis of the drawings, in the case of children and adolescents (Capella et al., 2015; Riessman, 2008). The software ATLAS.TI v7 was used to support analysis during this phase.

In the second phase, a method for case analysis was created and utilized (Capella \& Boddy, 2021). This analysis includes making a summary, where all the data associated with each case was integrated together, including all the interviews at the three data points during treatment $(6,12$ months and end of therapy) from all three perspectives (children and adolescents, caregivers and therapists). The case analysis method combined perspectives, while maintaining a central focus on the perspective of the children and adolescents. This allowed for a more comprehensive narrative of change and psychotherapy for each case.

In the third phase, a multi-case analysis was conducted, characterized by a systematic, comprehensive and in-depth analysis of multiple cases. This method allowed the researchers to compare and contrast in greater depth than would have been accomplished by analysing only individual cases (Rodríguez, Gil, \& García, 1999). This type of analysis is similar to the one reported in ideal-type analysis, where case summaries are contrasted looking at similarities and differences between them and constructing distinct groups; which have been used in psychotherapy research (Stapley, O'Keeffe, \& Midgley, 2021; O'Keeffe, Martin, Target, \& Midgley, 2019).

This paper reports on the third phase of analysis. The first and second phases of analysis are reported in another published articles (Capella et al., 2018; Capella \& Boddy, 2021) and in other works yet to be published. Looking mainly at the similarities in different cases about the moments of interviews, stages where identified, and analysing mainly the differences, distinct groups with different outcomes were identified.

In order to maintain trustworthy and high-quality criteria throughout the research process (Midgley, 2004; Riessman, 2008), triangulation strategies were implemented during all stages of analysis. Different members of the research team took part in the process of data analysis, thus validating the findings through an inter-subjective agreement. The case analysis was subject to credibility checks by other members of the team, and the distinct groups were derived by a process of consensusbuilding discussion by various members of the team (Stapley et al., 2021).

\section{Results}

The results discussed in this paper draw on the third phase of analysis and are presented in two main sections: i) stages of psychotherapeutic change; and ii) different outcomes of psychotherapeutic change. Building on the narratives which emerged from the different types of participants (children and adolescents, their caregivers and their therapists), a proposed CSA psychotherapeutic change model was drawn. This proposed model aims to shed light on the processes that the different cases lived throughout the therapeutic experience (see Figure 1). To maintain confidentiality, pseudonymous are used.

\section{Stages of psychotherapeutic change}

The majority of participants saw change as a process which involved progressive improvement. Participants commonly stated that change gradually developed over time and involved feeling better.

An inter-case analysis of the three moments of interviews identified three main stages of change during ther- 
apy: an initial stage, an intermediate stage and a final stage. These stages are characterized by aspects of the therapeutic intervention associated primarily with the themes approached during the process and the therapeutic work done in each stage.

It is important to note that while these perspectives on the stages of change come from multiple cases, they were largely observed by the cases that experienced the therapeutic process for 18 months or longer.

\section{Initial stage: The complexity of starting therapy}

The beginning of therapy and the change process were seen as a difficult period, causing fear, emotional discomfort, defensiveness and resistance toward therapy and therapists. However, resistance decreased as children and families became more familiar with the therapeutic space and the therapist, and as they developed a therapeutic relationship based on confidence, which increased their engagement with therapy. At this stage, therapy was seen mainly as a space for relief and emotional support. Also a focus on familiar work was developed at this stage. Initial changes identified in children and adolescents were improvements in their emotional wellbeing and feeling happier, and changes at a familial level in which there was an increase in family resources and a reduction in violent dynamics toward the child. However, participants recognized that there remained several pending changes at this stage.

\section{Intermediate stage: Starting to approach the child sexual abuse experience}

At this stage, the experience of sexual abuse was approached both directly and indirectly in therapy, addressing understandings of and feelings related to the sexual abuse experience. Starting to approach the CSA experience at this stage lead participants to encounter changes in their emotions toward the negative consequences of the abuse. In particular, they were able to express more clearly what happened with less pain and shame. This is also the stage in which several cases faced setbacks in the appearance of new symptoms in children and adolescents such as defiant behavior and depressive symptoms; caregivers noted that in some cases these symptoms were not present prior to therapy. However, in these cases, therapists also viewed these setbacks as improvements. For example, several children were characterized by their caregivers as being 'cheekier,' which therapists saw as an improvement since the children were more able to express their opinions. In the case of adolescents, depressive symptoms were observed, which appeared when they were able to recognize and approach their abusive experience. Overall, at this stage, participants thought more changes were needed.

\section{Final stage: Healing from child sexual abuse}

At this stage, changes were clearly seen and reinforced in therapy. Several children and adolescents and their caregivers reported profound changes related to the abuse, especially concerning healing from and reduced discomfort with the abuse. This was observed in the narratives of children and caregivers who perceived the abuse to be integrated into their lives and understood the CSA to be a past negative experience, which was remembered but not too often. At this stage, children and adolescents also began to recognize their personal resources and felt stronger and more able to face the sexual abuse and life in general. Caregivers displayed a sense of empowerment and the capability to deal with problems, particularly through the development of protective behaviours and actions toward their children. Moreover, at this stage, achieved changes were often projected into the future as participants felt that changes would continue after the therapy ended. It is important to note that caregivers also experienced change during the therapeutic process, and significantly, changes in children and adolescents and in

\section{Stages of psychotherapeutic change}

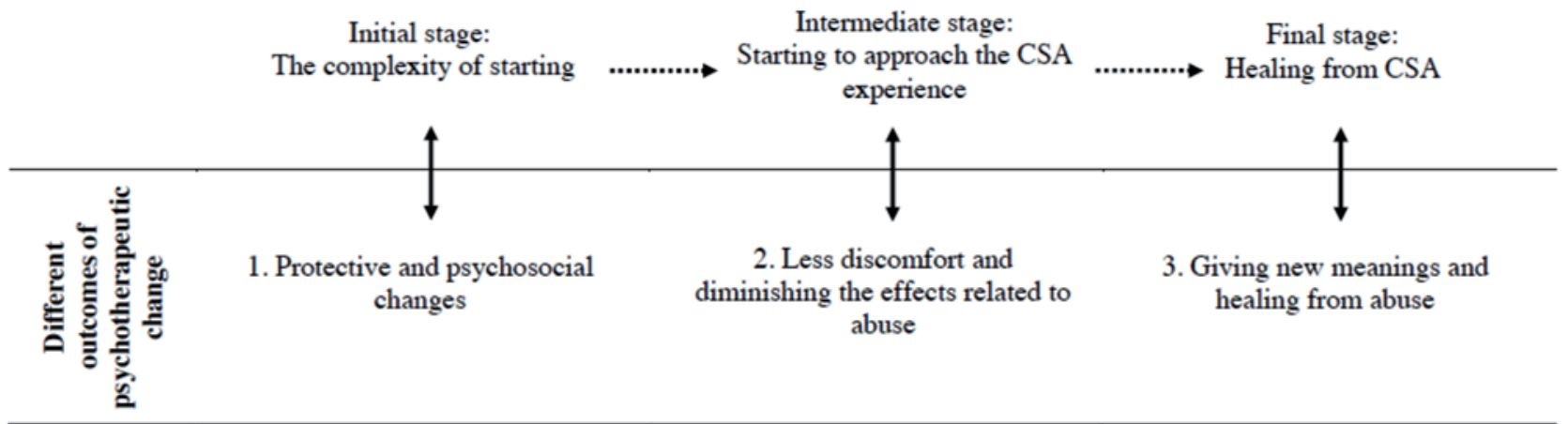

Figure 1. Child sexual abuse (CSA) psychotherapeutic change process model. 
caregivers influenced each other. For example, some caregivers reported that seeing their children feeling better about the abusive experience had an impact on their own emotions regarding the CSA, particularly through the experience of emotional relief. Caregivers changed when they saw changes in their children, and the caregivers' changes, in turn, benefited the children.

Case vignette: Trinidad. She was 14 years old at the beginning of therapy and had been repeatedly sexually abused by her father. She was no longer in contact with him and there was a legal case against him in progress. Trinidad was in therapy for one year and seven months and was accompanied to treatment by her mother. Her older brother (who did not live with her) disbelieved the abusive experience.

Initial stage: At the beginning of therapy, Trinidad presented depressive symptoms and behaviours of selfharm. She tried to avoid talking about her sexual abuse experience, and her mother also felt emotionally affected by her daughter's abuse. During this first stage of therapy, Trinidad started expressing unease about her brother's disbelief of her abuse even though she still experienced difficulties when talking about it. Her depressive symptoms diminished, and self-harm behaviours disappeared. However, Trinidad and her mother still felt more changes were needed as symptoms of anxiety appeared. Therapy was seen as a space of support and relief. Trinidad after 9 months of therapy stated:

[at the beginning] I was not well... [now] I am

happier... when I come here [to therapy] if there

are times I come here and I am sad, talking with

the psychologist makes me feel better, like I relief,

like I tell someone my things.'

Intermediate stage: After one year of therapy, remission of depressive symptoms persisted, but symptoms of anxiety had not diminished. Trinidad's relationships with peers improved as she became more open to others. She was also able to talk about the abuse in therapy and express feelings of guilt and her feelings about her brother disbelieving her. Although Trinidad felt that she was thinking less about the abusive experience, talking about it continued to produce a great deal of discomfort. Still, she and her mother felt more changes were needed at this stage. After 15 months of therapy Trinidad said:

'Now I am very well, much better than at the beginning ... I have a dog, I have a new friend, $\mathrm{hmm}$ ... now my mom is fine, and I am fine ... [therapy helps] in talking about things ... that you don't have to stay with everything inside you, you don't have to carry all the bad things with you ... I didn't like those bad things, I don't like to tell them very much [to psychologist], it's like I get sad.'

Final stage: At this stage, approaching the topic of abuse in therapy helped Trinidad to feel healed from it. In her last interview, after one year and seven months in therapy, she described the abuse as a past experience and con- veyed diminished feelings of guilt. While she described it as difficult, she also accepted and understood the disbelief of her brother, thus producing less discomfort about it. The remission of depressive symptoms continued while symptoms of anxiety disappeared, and she was able to analyse and understand her past behaviours of self-harm. Relationships with peers continued to improve as Trinidad felt more confident in this area and experienced a general sense of wellbeing. Her mother was less troubled and her sense of relief around the abuse grew as she perceived a process of healing both in herself and in her daughter. Trinidad and her mother felt that these changes would persist in the future.

'We have improved and overcoming things and now we are very well [and you feel coming here helped you with that?] yes... like overcoming it but not forgetting it ... it already happened ... and I also know it wasn't my fault ... it is in the past and now I am fine.' (Trinidad at the end of the therapeutic process)

\section{Different outcomes of psychotherapeutic change}

From the multi-case analysis, it was possible to identify different outcomes of psychotherapeutic change among the different cases, when participants described their experience of psychotherapeutic change, although, different cases concluded therapy at different times. The outcomes of psychotherapeutic change are understood as the way in which children and adolescents, their caregivers, and their therapists narrate and conceptualize their processes of change and healing from sexual abuse in psychotherapy.

Three key groups were identified with regard to outcomes. These three groups had different outcomes associated with changes related to the sexual abuse experience, displaying variations in the depths to which the abusive experience was addressed in therapy. The characteristics of these different outcomes of psychotherapeutic change are described. Also, after identifying the groups, the main psychosocial characteristics of each group and the therapeutic process were identified, thus, after describing the characteristics of the outcomes, it is followed by a description of the main characteristics of the group of cases identified in each type of outcome (see Table 3).

\section{Protective and psychosocial changes}

In these cases, changes were related to the improvement of protective and familial elements, such as family resources, the child's relationship with significant figures and the ending of violent dynamics toward the child. Some changes were observed at an individual symptomatic level as improvement in social behaviours, for example, expressing emotions more appropriately and decreasing aggressive behavior toward others. These changes initially occurred without establishing a link to the situation of sexual abuse. 
In this group, six cases were identified. The common characteristics among these cases were that the children were mostly between six and ten years old (only one adolescent was identified in this group), with an average age of 9.2 years old, and were mostly females. The experiences of abuse were diverse in this group, with unique, repeated and chronic experiences of abuse, by family or extrafamiliar members. However in two cases, the characteristics of the abuse weren't completely clear. They were mainly accompanied to therapy by their mothers, but also some on them with other figures (aunt and uncle, grandmother) with whom they lived with. In these cases, was common that complex familiar and psychosocial characteristics were present, such as intimate partner violence, lack of credibility towards the abuse of the child, among others.

In these cases, therapy lasted mainly between 14 to 24 months (in only the case of the adolescent therapy lasted 7 months), with an average time of 17.3 months. The psychotherapeutic process focused more intensely on working with the family rather than with the child individually, addressing predominantly family complexities, such as difficult bonds with caregivers, not protecting the child from the abuser and disbelieving the abuse. The therapeutic work with the child was not directly related to the sexual abuse experience. Some participants also identified difficulties with regard to continuity during psychotherapy due to changes of therapists and consequently prolonged periods of more than one month without psychological attention, which may have negatively affected the therapeutic alliance and willingness to attend therapy.

Case vignette: Tania. She was a 7-year-old girl who was sexually abused by her stepfather in repeated episodes. Her mother disbelieved the abusive experience, so Tania's aunt and uncle had taken legal custody of the girl. Throughout therapy, one of the most significant difficulties was Tania's constant demand to return to her mother's home even though she disbelieved the abuse. Thus, the therapy focused on assisting the caregivers to develop the appropriate tools to maintain care of the girl. The primary changes in this case were Tania's growing confidence to stay with her new family and adjust to the new environment and the bonds she created with her uncle and aunt, all achieved with the therapist's support. Therapy lasted 14 months with one month of interruption while the therapist was on medical leave. Tania and her uncle stated at the end of therapy:
'I am becoming fond of my uncle.' (Tania)
'We tell her we are one family, and we all have to do things, we make our bed, your cousin makes his bed, you make your bed, we all help each other... and she was like 'Why me? Why me?' [and we say] 'Because you belong to this family and we all have to do it'. '(Tania's uncle at the end of therapy)

\section{Less discomfort and diminishing effects related to abuse}

This second group included cases which presented positive changes related to the abusive experience, particularly in decreased discomfort with the experience and diminished negative effects related to the abuse. Important changes were identified at a symptomatic level in which improvements were recognized at the social level and in self-perception. That is, the children and adolescents were able to visualize their own resources such as a sense of empowerment and security, which allowed for a return to more normal routines and establish more satisfactory relationships with others. However, it was not possible to

Table 3. Characteristics of the group of cases identified in each type of outcome of psychotherapeutic change.

\begin{tabular}{|c|c|c|c|}
\hline & $\begin{array}{l}\text { 1. Protective and } \\
\text { psychosocial changes }\end{array}$ & $\begin{array}{l}\text { 2. Less discomfort and } \\
\text { diminishing the effects related to abuse }\end{array}$ & $\begin{array}{l}\text { 3. Giving new meanings and } \\
\text { healing from abuse }\end{array}$ \\
\hline Number of cases & $\mathrm{n}=6$ & $\mathrm{n}=13$ & $\mathrm{n}=9$ \\
\hline Age (average in years) & 9.2 & 10.8 & 10.3 \\
\hline Gender (percentage) & $\begin{array}{c}\text { Females } 83 \% \\
\text { Males } 17 \%\end{array}$ & $\begin{array}{c}\text { Females } 69 \% \\
\text { Males } 31 \%\end{array}$ & $\begin{array}{c}\text { Females } 89 \% \\
\text { Males } 11 \%\end{array}$ \\
\hline Offender & $\begin{array}{l}\text { Intrafamilial }(66 \%) \text {, } \\
\text { extrafamilial }(17 \%) \text {, } \\
\text { unknown }(17 \%)\end{array}$ & $\begin{array}{c}\text { Intrafamilial }(69 \%) \text {, } \\
\text { extrafamilial }(23 \%) \text {, } \\
\text { unknown }(n=8 \%)\end{array}$ & Intrafamilial $(100 \%)$ \\
\hline Time in therapy (average in months) & 17.3 & 19.6 & 20.6 \\
\hline Caregiver & $\begin{array}{l}\text { Mothers }(n=4), \\
\text { grandmother }(n=1), \\
\text { aunt and uncle }(n=1)\end{array}$ & $\begin{array}{l}\text { Mothers }(n=9) \\
\text { grandmothers }(n=4)\end{array}$ & $\begin{array}{l}\text { Mothers }(n=8) \\
\text { father }(n=1)\end{array}$ \\
\hline Therapist's age (average in years) & 30.5 & 31.3 & 29.6 \\
\hline Theoretical approach & $\begin{array}{c}\text { Systemic }(66 \%) \\
\text { cognitive-constructivist }(34 \%)\end{array}$ & $\begin{array}{c}\text { Systemic }(58 \%), \\
\text { cognitive-constructivist }(25 \%) \text {, } \\
\text { psychoanalytic approach }(17 \%)\end{array}$ & $\begin{array}{c}\text { Systemic }(37.5 \%), \\
\text { cognitive-constructivist }(50 \%), \\
\text { psychoanalytic approach }(12.5 \%)\end{array}$ \\
\hline
\end{tabular}


observe changes in the meanings related to the abuse or in the feeling of having overcome it. Also, some cases still present some emotional symptoms at the end of therapy. Protection issues were also addressed and resolved in most of these cases through significant therapeutic changes of the caregivers who became more protective and receptive to the needs of the child or adolescent, generating a significant improvement in their bond.

This group was composed of 13 cases with children and adolescents between six to 16 years old, with an average age of 10.8 years old. They experience different types of abuse, including mainly intrafamiliar abuses, but also extrafamiliar abuses, in a unique, repeated or chronic manner. In one case, the characteristics of the abuse weren't completely clear. They were mainly accompanied to therapy by their mothers, however 4 of them were accompanied by their grandmothers with whom they lived with.

In this cases therapy lasted between 12 and 26 months with an average of 19.6 months. Therapy focused on working and approaching directly or indirectly the abusive experience and its effects. However, in the majority of these cases, there were disruptions to the therapeutic process resulting from a change of therapist and periods without intervention due to a lack of professionals and low attendance to sessions by the family group.

Case vignette: Vicente. He was an 8-year-old boy who was sexually abused by his maternal grandfather in repeated episodes. His mother accompanied him to therapy, and he had a change of therapist approximately four months after the start of the therapeutic process. There were interruptions to therapy due to the non-attendance of the child and his mother to multiple sessions. The observed changes demonstrated an improvement in the mother's ability to identify her child's needs and provide him with more emotional support. The child also displayed greater tranquillity when thinking about the abusive situation, demonstrating a sense of safety and control over the environment. A problematic aspect of Vicente's case was that his grandmother remained with the aggressor, and consequently there were restrictions on how often he could see her during his time in therapy, which lasted 18 months. When asked how therapy helped him with the abuse, Vicente stated:

(...) not to be sad, to be happier ... When I started, I felt very bad because I felt like threatened and sad...sad because I was away from a relative of mine... [and at the end of therapy] ... happy, because I could see her [grandmother] again, but without the person who hurt me.' (Vicente at the end of therapy)

\section{Giving new meanings to and healing from abuse}

The third group of cases demonstrated that they had been able to give new meanings to the experience of sexual abuse, expressing narratives of healing. Healing was described as feeling less guilty about the abuse and feeling as though it were a past experience that they could recall without the pain they felt at the beginning. Participants expressed that they would never forget the experience, but that they could live with it and could focus on future plans in which the abuse was not the centre of their life. They felt empowered to live their lives and move forward. Children and adolescents also described greater feelings of security and restored confidence in themselves and their environment. Thus, remission of symptoms was observed in all cases. Caregivers expressed a deeper understanding of the sexual abuse, problematizing it in relation to risk factors and displaying greater emotional support abilities toward the children or adolescents. Additionally, when issues of protection arose, they were resolved.

This group included nine cases, primarily adolescents or children who were more than nine years old at the beginning of therapy (only one child was 7 years old), with an average of 10.3 years old. All of them were accompanied to therapy with their mothers or in one case the father, with whom they lived with. The abuse experienced were all in the intrafamiliar context and were a unique experience or repeated or chronic abuses.

These cases were in therapy for more than 18 months, in a range of 18 to 28 months, with an average of 20.6 months. Children and adolescents were accompanied by their caregivers to therapy, which provided a supportive familial environment. In these cases, a clear therapeutic approach was observed to be linked to the ability to address the experience of sexual abuse, leading the therapeutic process to address all the different aspects associated with the experience. Also, few interferences in the process were seen (no change of therapist or only very early in the process).

Case vignette: Amalia. She was a 12-year-old girl who was sexually abused in a chronic manner by her paternal grandfather. The father disbelieved the abuse, distancing himself from Amalia and due to this, Amalia went through a grieving process for her relationship with her father. Participants reported that maternal support was essential in this case, as well as Amalia's personal effort. By the end of therapy, Amalia had integrated the experience of abuse into her life story, understanding that the situation did not define her. Her mother and therapist observed her to be empowered with future plans. The therapeutic bonding and the techniques used were highlighted by Amalia as helpful tools to face the abuse. Although there was a change in therapist three months after beginning, therapy lasted 18 months. When asked how she felt at the end of therapy, Amalia stated:

'I don't feel a weight on me, which was being hurt, the pain I had and all that, but now I don't feel any of that ... I feel that I healed, I healed, my wounds, that is, the scars that I have are because I fought.' (Amalia at the end of therapy) 


\section{Discussion and conclusions}

Results shed light on the process and evolution of subjective psychotherapeutic change in children and adolescents who have been sexually abused. CSA psychotherapeutic change appears as a dynamic and gradual process in which the different stages and outcomes of psychotherapeutic change are interrelated. In the first set of results, obtained through three interview moments, identified three main stages of therapeutic change in which changes take place in a progressive manner similar to stages described previously in psychotherapy research with adults (Echavarrí et al., 2009; Krause et al., 2007; Levitt, Butler, \& Hill, 2006) and with therapists of victims of sexual abuse (Aguila et al., 2016).

In the first stage of therapeutic change, an initial relief could be observed as emotional changes appeared following initial difficulties in attending therapy. In an intermediate stage, the therapeutic work and changes started to deepen, and the abusive experience was approached, allowing more complex changes to emerge. It was interesting that at this stage, difficulties appeared which were interpreted as setbacks by caregivers but as improvements by the therapists. This finding highlights the importance of including different perspectives when exploring change from the participants' perspectives and emphasizes the idea that change is a gradual and nonlinear process (Altimir et al., 2010; Krause, 2011). Furthermore, although difficulties may appear when the abuse is approached in therapy, this seems to be relevant to the healing taking place (Capella et al., 2016; Nelson-Gardell, 2001; Tichelaar et al., 2020). The final therapeutic stage involved the consolidation of the changes; that is, an overall feeling of the possibility of overcoming the abuse and a more positive view of oneself and the future. This stage demonstrated the possibility of having more stable and in-depth changes related to giving new meanings to the abuse.

The second set of results identified three outcomes of psychotherapeutic change, that describe different types of changes which can be accomplished through the therapeutic process. Although participants experienced therapy for varying lengths of time and ended therapy at different stages, the outcomes of change also appear to be closely related to psychosocial characteristics of the cases and the therapeutic process.

The first group of outcomes were predominantly composed of cases with complex familial and psychosocial issues. The process of generating protective conditions for the children's welfare became a therapeutic process itself, although the abusive experience was not approached in therapy. This cases in average were the youngest of the three groups and therapies even though were long processes, within the three groups were the shorter ones. When analysing the cases who dropped out of therapy from this study, which were mainly adolescents (Capella et al., 2020), there were also cases with complex familial situations. Further research could deepen the understanding of factors related to differences between cases that drop out of therapy and the ones that completed therapy.

In the second and third groups of outcomes, the central aspect of psychotherapeutic change was related to diminishing the negative effects of the abuse. However, narratives of overcoming the abusive experience were not present in the second group. In this second group, there was instability in the therapeutic process related to a change of therapist, non-attendance, etc., which could have prevented more in-depth changes from occurring. Alternately, in the third group, it was possible to observe strong and clear narratives of giving new meanings to the abusive experience and healing from CSA. Certain characteristics of the cases and the therapeutic process may have influenced the success of the process in the third group such as longer periods of therapy, having a consistent therapist and the participants being primarily children and adolescents with family support and accompanied to therapy by one of the progenitors.

Although we can see some small differences in who was the aggressor in the three groups, it is difficult to analyse these in more depth, due that most of the cases in the sample, have been abused in a family context. Due to the importance that some studies have shown due to the aggressor figure in the consequences of the abuse (Guerra et al., 2018), and the possible influence this can have in the therapeutic process, this should be deepened in future research. Also, the therapists' characteristics (for example, experience, theoretical orientation) and their influence on the therapeutic process could be studied further.

It is clear that the two sets of results, stages and outcomes of psychotherapeutic change, are connected (see Figure 1). It was possible to observe initial changes in emotions and symptoms at a first stage. A group with psychosocial changes was identified, which seemed to build on changes from the initial stage of therapy. Psychosocial changes appeared to be achievable in cases with complex psychosocial characteristics that attended mainly more than 14 months of therapy. These cases may require additional time for deeper changes to occur, particularly with regard to changes related to the sexual abuse experience. Furthermore, in the second stage, changes related to approaching more deeply the topic of abuse were connected to the therapeutic outcome of diminishing the effects of abuse. In the final stage of therapy, changes were observed to be related to healing from abuse, which also appeared in the third group of outcomes.

When all these results are viewed together, it appears that in order to create new meanings and overcome the abusive experience, there are certain, necessary factors (Capella \& Gutierrez, 2014; Narang, 2016). That is, participants experienced a sense of healing from CSA in the final stage of therapy when therapy and therapists were stable, when they had attended therapy for 18 months or longer, when the topic of abuse was approached in depth 
and when they had support from caregivers. Tichelaar et al. (2020) also found that focusing on creating a narrative of the child's traumatic experience could be an important treatment component. However, these findings would benefit from further research into factors that may support or hinder psychotherapeutic change in cases of CSA, particularly research from the participants' perspectives. Also, research that deepens on the therapeutic strategies used can help to understand the therapeutic process that favours healing. There is scarce research that study treatment components (Tichelaar et al., 2020). The participants who achieved a sense of healing from the abuse were primarily adolescents and children over nine years old at the beginning of therapy, which raises the question of how healing takes place in younger children. Also, a limitation of this study is that we include a wide age range, so future studies could study narrower groups to see if these stages and outcomes are the same. Further research into potentially different research methodologies is necessary to understand how younger children may achieve healing from CSA. Interestingly in this study no important differences between the abusive experiences lived by children and adolescents were seen between the groups, however, this could be studied further as well.

These results reveal general guidelines for the therapeutic process in cases of child sexual abuse with regard to the stages of therapy and the conditions required to achieve the various outcomes of change. Key findings suggest that clinical practices need to focus on: i) creating comfortable spaces for both children and their caregivers to approach the CSA; ii) considering the children and adolescents and their caregivers' timings; iii) promoting the stability and regularity of therapy and therapists; and iv) understanding and addressing the impact of personal and complex psychosocial and familial characteristics. Also, implications for the organization of services arises, such as implementing ways for preventing changes of therapists and periods without intervention. Future research should consider narrowing in on specific guidelines for psychotherapy in cases of CSA treatment and potential intervention strategies.

The results of this study demonstrate the complexity of therapy in these cases and the diversity of experiences in which multiple elements are involved in achieving change, from the psychosocial and developmental characteristics of the child or adolescent to the way the therapeutic process is developed and the length of therapy, among others. Moreover, it is important to consider that despite the research's focus on the psychotherapeutic process, other studies highlight the importance of extratherapeutic factors, which are also important for achieving healing from abuse (Capella et al., 2016, 2018; Draucker et al., 2011; Foster \& Hagedorn, 2014; Jessiman et al., 2017; Nelson-Gardell, 2001). As in other research, findings from this study indicate that family support and caregivers' consistent work in therapy are important factors for change to take place (Nelson-Gardell, 2001).
The inability of this study to control variables related to the therapeutic process should not be considered a limitation, but rather a strength as it allowed for the study of therapies and the evolution of change in a natural setting, from various psychotherapeutic theoretical approaches. It is also important to highlight participants' views and understandings of psychotherapy and to integrate the perspectives of caregivers, therapists, and children and adolescents, as the main actors, in order to provide a more holistic picture of change and to develop guidelines for therapy.

\section{References}

Águila, D., Lama, X., Capella, C., Rodríguez, L., Dussert, D., Gutiérrez, C. \& Beiza, G. (2016). Narratives from therapists regarding the process of psychotherapeutic change in children and adolescents who have been victims of sexual abuse / Narrativas de terapeutas sobre el proceso de cambio psicoterapéutico en niños, niñas y adolescentes que han sido víctimas de agresiones sexuales. Estudios de Psicología, 37(2-3), 344-364. doi:10.1080/02109395.2016.1204780.

Alamo, N. (2019). Contenidos y evolución del cambio en la psicoterapia con niños y niñas [Content and evolution of change in psychotherapy with children]. (Doctoral Thesis). Pontificia Universidad Católica de Chile, Santiago, Chile.

Altimir, C., Krause, M., de la Parra, G., Dagnino, P., Tomicic, A., Valdés, N. \& Vilches, O. (2010). Clients', therapists', and observers' agreement on the amount, temporal location, and content of psychotherapeutic change and its relation to outcome. Psychotherapy Research, 20(4), 472-487. doi:10.1080/10503301003705871.

Areas, M., Olivera, J., \& Roussos, A. (2020). Cambio y psicoterapia: la perspectiva del niño [Change and Psychotherapy: The Child's Perspective]. Diversitas: Perspectivas en Psicología, 16(2). doi:10.15332/22563067.5553.

Banyard, V., \& Williams, L. (2007). Women's voices on recovery: A multi-method study of the complexity of recovery from child sexual abuse. Child Abuse and Neglect, 31(3), 275-290. doi:10.1016/j.chiabu.2006.02.016.

Barth, J., Bermetz, L., Heim, E., Trelle, S., \& Tonia, T. (2013). The current prevalence of child sexual abuse worldwide: A systematic review and meta-analysis. International Journal of Public Health, 58(3), 469-483. doi:10.1007/s00038-0120426-1.

Capella, C. \& Boddy, J. (2021). Listening to the opinista? Relational understandings of voice and silence in a multiperspective narrative study of child psychotherapy. Children \& Society, 35, 835-849. doi:10.1111/chso.12458.

Capella, C. \& Gutiérrez, C. (2014). Psicoterapia con niños/as y adolescentes que han sido víctimas de agresiones sexuales: Sobre la reparación, la resignificación y la superación. Psicoperspectivas, 13(3), 93-105. doi:10.5027/PSICOPERSPECTIVAS-VOL13-ISSUE3-FULLTEXT-348.

Capella, C., Gutiérrez, C., Rodríguez, L. \& Gómez, C. (2018). Change during psychotherapy: the perspective of children and adolescents who have been sexually abused. Research in Psychotherapy: Psychopathology, Process and Outcome, 21(1), 24-39. doi:10.4081/ripppo.2018.288.

Capella, C., Lama, X., Rodriguez, L., Aguila, D., Beiza, G., Dussert D. \& Gutierrez, C. (2016). Winning a race: Narratives of healing and Psychotherapy in children and adoles- 
cents who have been sexually abused. Journal of Child Sexual Abuse, 25(1), 73-92. doi:10.1080/10538712.2015. 1088915.

Capella, C., Núñez, L., Vásquez, V. \& Fuentes, S. (2020). Adherencia o deserción de adolescentes en psicoterapia por agresiones sexuales: la perspectiva de sus terapeutas. Revista CES Psicología, 13(3), 124-141. doi:10.21615/cesp.13.3.8.

Capella, C., Rodriguez, L., Aguila, D., Dussert, D., Lama, X., Gutierrez, C. \& Beiza, G. (2015). Storied images of psychotherapeutic change: Approaching children's voices through drawings. Research in Psychotherapy: Psychopathology, Process and Outcome, 18 (2), 141-151. doi:10.7411/RP.2015.109.

Carlberg, G., Thorén, A., Billström, S., \& Odhammar, F. (2009). Children's expectations and experiences of psychodynamic child psychotherapy. Journal of Child Psychotherapy, 35(2), 175-193. doi:10.1080/00754170902996130.

Castrillón, C. (2020). Momentos significativos en psicoterapia con niños: un estudio sobre procesos de cambio [Significant Moments in Psychotherapy with Children: A Study on Change Processes]. Rev. CES Psico, 13(3), 88-106. doi:10.21615/cesp.13.3.6.

Cohen, J. A., \& Mannarino, A. P. (1998). Interventions for sexually abused children: Initial treatment outcome findings. Child Maltreat, 3(1), 17-26. doi:10.1177/1077559598003001002.

Cohen, J. A., Mannarino, A. P., \& Deblinger, E. (Eds.). (2012). Trauma-focused CBT for children and adolescents: Treatment applications. New York, NY: The Guilford Press.

Draucker, C. B., Martsolf, D. S., Roller, C., Knapik, G., Ross, R., \& Stidham, A. W. (2011). Healing from childhood sexual abuse: A theoretical model. Journal of Child Sexual Abuse, 20(4), 435-466. doi:10.1080/10538712.2011.588188.

Dussert, D., Capella, C., Lama, X., Gutiérrez, C., Águila, D., Rodríguez, L. \& Beiza, G. (2017). Narrativas de Padres de Niños, Niñas y Adolescentes que Han Finalizado Psicoterapia por Agresiones Sexuales: Un Proceso de Superación Conjunta. Psykhe, 26(1), 1-14, doi:10.7764/psykhe.26.1.916.

Echavarrí, O., González, A., Krause, M., Tomicic, A., Pérez, C., Dagnino, P., De la Parra, G., et al., (2009). Cuatro terapias psicodinámicas breves exitosas estudiadas a través de los indicadores genéricos de cambio [Four successful brief psychodynamic therapies studied through the generic change indicators]. Revista Argentina de Clínica Psicológica, 28(1), 5-19.

Elliott, R. (2008). Research on client experiences of therapy: Introduction to the special section. Psychotherapy Research 18(3), 239-242. doi:10.1080/10503300802074513.

Farr, J., Edbrooke-Childs, J., Town, R., Pietkiewicz, D., Young, I., \& Stapley, E. (2021). Counseling for Young People and Families Affected by Child Sexual Exploitation and Abuse: A Qualitative Investigation of the Perspective of Young People, Parents, and Professionals. Journal of Child Sexual Abuse doi:10.1080/10538712.2020.1848959.

Fernandez, O.M., Krause, M., \& Pérez, J.C. (2016). Therapeutic alliance in the initial phase of psychotherapy with adolescents: different perspectives and their association with therapeutic outcomes. Research in Psychotherapy: Psychopathology, Process and Outcome, 19(1), 1-9. doi:10.4081/ripppo. 2016.180.

Foster, J. \& Hagedorn, B. (2014). Through the Eyes of the Wounded: A Narrative Analysis of Children's Sexual Abuse Experiences and Recovery Process. Journal of Child Sexual Abuse, 23, 538-557. doi:10.1080/10538712.2014.918072.
Guerra, C., Farkas, C. \& Moncada, L. (2018). Depression, anxiety and PTSD in sexually abused adolescents: Association with self-efficacy, coping and family support. Child Abuse \& Neglect, 76, 310-320. doi:10.1016/j.chiabu.2017.11.013.

Gómez, E., Cifuentes, B. \& Sieverson, C. (2010). Características asociadas al abuso sexual infantil en un programa de intervención especializada en Santiago de Chile [Characteristics associated to child sexual abuse in a specialized intervention program from Santiago, Chile]. SUMMA Psicológica UST, 7(1), 91.104. doi:10.18774/448x.2010.7.114.

Gonçalves, M., Matos, M., \& Santos, A. (2009). Narrative therapy and the nature of 'innovative moments' in the construction of change. Journal of Constructivist Psychology, 22(1), 1-23. doi:10.1080/10720530802500748.

Guha, A., Luebbers, S., Papalia, N., Ogloff, J. (2019). A followup study of mental health service utilisation in a cohort of 2433 sexually abused Australian children utilising five years of medical data. Child Abuse \& Neglect, 90, 174-184. doi:10.1016/j.chiabu.2019.01.015.

Hetzel-Riggin, M., Brausch, A., \& Montgomery, B. (2007). A meta-analytic investigation of therapy modality outcomes for sexually abused children and adolescents: An exploratory study. Child Abuse and Neglect, 31(2), 125-141. doi:10.1016/j.chiabu.2006.10.007.

Jessiman, T., Hackett, S., \& Carpenter, J. (2017). Children's and carers' perspectives of a therapeutic intervention for children affected by sexual abuse. Child and Family Social Work, 22(2), 1024-1033. doi:10.1111/cfs.12322.

Krause, M. (2011). Psicoterapia y cambio. Una mirada desde la subjetividad [Change and psychotherapy. A look from the subjetivity] ( $\left.2^{\circ} \mathrm{ed}\right)$. Santiago: Ediciones Universidad Católica.

Krause, M., De la Parra, G., Arístegui, R., Dagnino, P., Tomicic, A., Valdés, N., Echávarri, O., et al. (2007). The evolution of therapeutic change studied thtough generic change indicators. Psychotherapy Research, 17(6), 673-689. doi:10.1080/10503300601158814.

Levitt, H., Butler, M., Hill, T. (2006). What clients find helpful in psychotherapy: Developing principles for facilitating moment to moment change. Journal of Counseling Psychology, 53(3), 314-324. doi:10.1037/0022-0167.53.3.314.

Midgley, N. (2004). Sailing between Scylla and Charybdis: Incorporating qualitative approaches into child psychotherapy research. Journal of Child Psychotherapy, 30(1), 89-111. doi:10.1080/0075417042000205814.

Midgley, N., et al. (2018). Introduction to the special section on child and adolescent psychotherapy research. Psychotherapy Research, 28(1), 1-2. doi:10.1080/10503307.2017.1380864.

Narang, J. (2016). A Grounded Theory Analysis of Therapeutic Interventions Practiced by Professionals in India and the UK with Child and Adolescent Survivors of Sexual Abuse (Doctoral Thesis). University of Edinburg.

Nelson-Gardell, D. (2001). The voices of victims: surviving child sexual abuse. Child and Adolescent Social Work Journal, 18(6), 401-416. doi:10.1023/A:1012936031764.

O'Keeffe, S., Martin, P., Target, M. \& Midgley, N. (2019). I just stopped going: A mixed methods investigation into types of therapy dropout in adolescents with depression. Frontiers in Psychology, 10(75), 1-14. doi:10.3389/fpsyg.2019.00075.

Riessman, C. (2008). Narrative methods for the human sciences. California, USA: Sage Publications.

Rodríguez, G., Gil, J. \& García, E. (1999). Metodología de la Investigación Cualitativa [Methodology of the Qualitative Research]. Málaga: Aljibe. 
Sánchez-Meca, J., Rosa-Alcázar, A., \& López-Soler, C. (2011). The psychological treatment of sexual abuse in children and adolescents: A meta-analysis. International Journal of Clinical and Health Psychology, 11(1), 67-93.

Stapley, E., O'Keeffe, S. \& Midgley, N. (2021). Essentials of ideal-type analysis: A qualitative approach to constructing typologies. American Psychological Association. doi:10.1037/0000235-001.

Servicio Nacional de Menores [SENAME] (2019). Orientación técnica: línea programas de Protección Especializada en Maltrato y Abuso Sexual Grave (PRM) [Technical guidelines: specialized protection programs in maltreatment and sexual abuse (PRM)]. Available from: https:// www.sename.cl/web/wp-content/uploads/2019/05/Orientaciones-Tecnicas-PRM.pdf Accessed: 30 ${ }^{\text {th }}$ August 2021.
Tichelaar, H., Deković, M., \& Endendijk, J. (2020). Exploring effectiveness of psychotherapy options for sexually abused children and adolescents: a systematic review of randomized controlled trials. Children and Youth Services Review, 119. doi:10.1016/j.childyouth.2020.105519.

Valles, M. (2003). Técnicas cualitativas de investigación social [Qualitative techniques of social research]. Madrid: Editorial Síntesis.

Zarrella, I., Russolillo, L., Caviglia, G. \& Perrella, R. (2017). Continuity and discontinuity between psychopathology of childhood and adulthood: a review on retrospective and prospective studies. Research in Psychotherapy: Psychopathology, Process and Outcome, 20, 101-109. doi:10.4081/ripppo.2017.248. 